УДК 541.64

DOI 10.18101/2306-2363-2020-1-4-10

\title{
СИНТЕЗ И ИССЛЕДОВАНИЕ АРОМАТИЧЕСКИХ ПОЛИИМИНОЭФИРОВ
}

(С Могнонов Д. М.

доктор химических наук, профессор,

Байкальский институт природопользования СО РАН

Россия, 670047, г. Улан-Удэ, ул. Сахьяновой, 6

Бурятский государственный университет имени Доржи Банзарова

Россия, 670000, г. Улан-Удэ, ул. Смолина, 24а

E-mail: dmog@mail.ru

\section{(C) Аюрова О. Ж.}

кандидат технических наук, старший научный сотрудник, Байкальский институт природопользования СО РАН

Россия, 670047, г. Улан-Удэ, ул. Сахьяновой, 6

Бурятский государственный университет имени Доржи Банзарова

Россия, 670000, г. Улан-Удэ, ул. Смолина, 24а

E-mail: chem88@mail.ru

( ) Ильина О. В.

кандидат технических наук,

Байкальский институт природопользования СО РАН

Россия, 670047, г. Улан-Удэ, ул. Сахьяновой, 6

\section{(C) Хахинов В. В.}

доктор химических наук, профессор,

Бурятский государственный университет имени Доржи Банзарова

Россия, 670000, г. Улан-Удэ, ул. Смолина, 24a

E-mail: khakhinov@mail.ru

Проведен синтез ароматических полииминоэфиров путем поликонденсации бисимидоилхлоридов с диаминами. Определены оптимальные условия процессов поликонденсации с различными нуклеофилами. Реакцией неравновесной поликонденсации имидоилхлоридов моно- и дикарбоновых кислот с бисфенолами получены новые полимеры, строение которых установлено методами элементного анализа и ИКспекстроскопии. Показано, что полимеры обладают высокой термостойкостью. Исследованы пресс-материалы на их основе, которые характеризуются высокими деформационно-прочностными показателями, сравнимыми с материалами на основе ароматических полиамидов и полибензимидазолов.

Ключевые слова: неравновесная поликонденсация; высокотермостойкие полимеры; диамины; полииминоэфиры; полибензимидазолы; пресс-материалы; деформационнопрочностные показатели,

Для цитирования: Могнонов Д. М., Аюрова О. Ж., Ильина О. В., Хахинов В. В. Синтез и исследование ароматических полииминоэфиров // Вестник Бурятского государственного университета. Химия. Физика. 2020. Вып. 1. С. 4-10. 
Могнонов Д. М., Аюрова О. Ж., Ильина О. В., Хахинов В. В. Синтез и исследование ароматических полииминоэфиров

Сегодня термостойкие полимеры приобрели чрезвычайно важное значение благодаря удачному сочетанию исключительно высоких термических свойств с хорошими эксплуатационными характеристиками материалов на их основе.

Наиболее термостойкими полимерами, согласно сформулированным основным принципам конструирования высокотермостойких макромолекул, являются полигетероарилены, которые характеризуются содержанием в макроцепях бензоидных группировок наряду с гетероциклическими и/или гетероатомными фрагментами [1-4].

К их числу относятся термостойкие полиароматические азометины: полишиффовы основания, поликетанилы, поликетазины, полидиазины, поликарбодиимиды $[1,2]$. Эти «классические» полиазометины ввиду отсутствия плавкости и растворимости непригодны для переработки в изделия, что, вероятно, явилось причиной ограниченного к ним интереса.

В этой связи, представляет интерес высокомолекулярные ароматические соединения с повторяющимися фрагментами $-\mathrm{NH}-\mathrm{C}(\mathrm{R})=\mathrm{N}-$. Одним из основных путей синтеза полимеров подобного строения является поликонденсация бисимидоилхлоридов общей формулы $\mathrm{R}_{1}\left[\mathrm{C}(\mathrm{X})=\mathrm{NAr}_{2}\right]$, где $\mathrm{X}=$ Hal с диаминами [5-7].

Для получения новых полимеров представлялось целесообразным использовать бис-имидоилхлориды в процессах поликонденсации с другими нуклеофилами.

\section{Экспериментальная часть}

Бис-фенолы, коммерческие чистые продукты фирмы «Aldrich», использовали без предварительной очистки.

Имидоилхлориды моно- и дикарбоновых кислот синтезировали в соответствии с методикой [8].

Полииминоэфиры (ПЭИ) синтезировали в трехгорлой колбе (50 мл), снабженной механической мешалкой, капельной воронкой и трубками для ввода инертного газа (аргон). Загружали последовательно, с одновременной продувкой аргона, 0,01 М бис-фенола и 20 мл N-метилпирролидона (N-MП), смесь гомогенизировали. Затем при интенсивном перемешивании добавляли $0,02 \mathrm{M}$ триэтиламина и $0,01 \mathrm{M}$ имидоилхлорида. Колбу с реакционной смесью погружали в баню и температуру повышали до $130-140^{\circ} \mathrm{C}$. Через $13-14$ ч реакционную смесь выливали в $2 \%$-ный водный раствор аммиака, осадок отфильтровывали промывали последовательно 0,5\%-ными растворами $\mathrm{Na}_{2} \mathrm{CO}_{3}, \mathrm{HCl}$ и $\mathrm{H}_{2} \mathrm{O}$ до $\mathrm{pH}$, сушили в вакуум-шкафу при $80^{\circ} \mathrm{C}$ до постоянной массы.

ИК спектроскопические исследования выполняли на ИК-спектрометре ALPHA (Bruker, Германия) с приставкой МНПВО с кристаллом ZnSe в диапазоне волновых чисел 4000-600 $\mathrm{cm}^{-1}$.

Приведенную вязкость растворов ПИЭ определяли по ГОСТ 18249-72 в чистом растворителе ДМАА при $20^{\circ} \mathrm{C}$, концентрация ПИЭ 0,5 г/дл.

Термомеханический анализ ПИЭ выполняли на модифицированном приборе Цетлина при нагрузке 0,33 МПа, скорость нагревания $100^{\circ}$ ч.

Динамический термогравиметрический анализ ПИЭ выполняли на синхронном термическом анализаторе STA 449C (Netzsch, Германия) при скорости нагревания $5 \%$ мин, на воздухе. 
Компрессионные материалы на основе ПИЭ были получены из порошков полимера (без наполнителя) прямым прессованием при температуре $245-400^{\circ} \mathrm{C}$ и удельном давлении 75 МПа.

Прочность при разрыве пресс-материалов определяли по ГОСТ 14236-81 на универсальной разрывной машине Instron 3367 (США), образец-лопатка 5А, скорость подвижных захватов 100 мм/мин.

Ударную вязкость пресс-материалов определяли на маятниковом копре ПСВ0.4 , образец 50 × 6 × 4 мм.

\section{Результаты и обсуждение}

Применение бис-имидоилхлоридов в реакциях с бис-фенолами привело к получению новых ароматических полиазометинов - полииминоэфиров, согласно схемам:

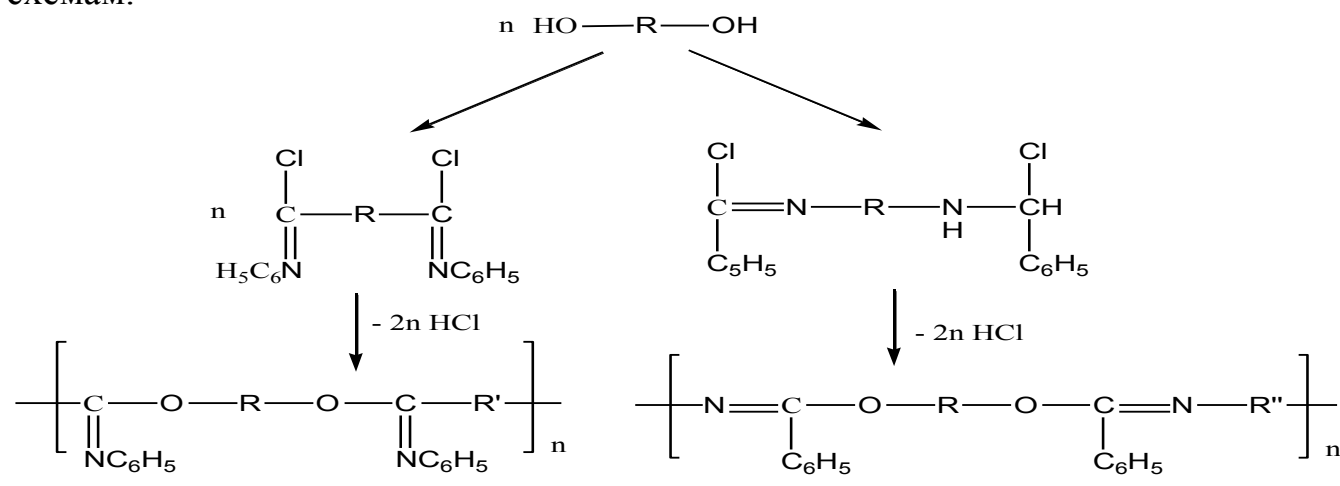

поли-(N-фенил)иминоэфир (N-ПИЭ) поли-(С-фенил)иминоэфир (С-ПИЭ)

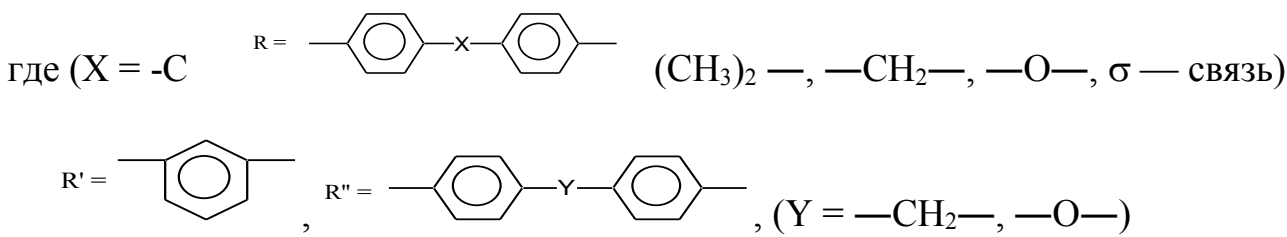

Поликонденсацию мономеров выполняли в высокополярных апротонных растворителях (ДМАА или N-MП), служащих одновременно акцепторами выделя-

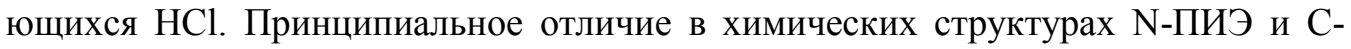
ПИЭ заключается в их изомерии. $\mathrm{B} \mathrm{N}$-ПИЭ двойная $\mathrm{C}=\mathrm{N}$ связь боковая, тогда как в С-ПИЭ она включается в основную полимерную цепь, что несомненно должно отразиться на химических и физико-химических свойствах этих полимеров.

Зависимость приведенной вязкости и выхода ПИЭ от температуры и концентрации мономеров изучали на примере взаимодействия 4,4-дифенилолпропана и $\mathrm{N}, \mathrm{N}$-дифенилизофталимидоилхлорида. Из рис. 1 видно, что лучшим растворителем для получения высокомолекулярных ПИЭ является N-MП. 
Могнонов Д. М., Аюрова О. Ж., Ильина О. В., Хахинов В. В. Синтез и исследование ароматических полииминоэфиров

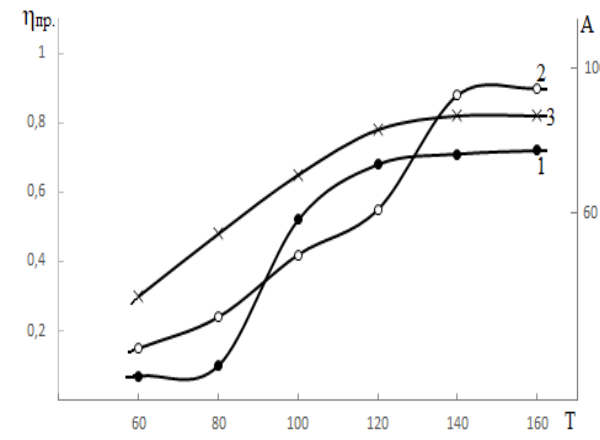

Рис. 1. Влияние температуры $\mathrm{T},{ }^{\circ} \mathrm{C}$ на приведенную вязкость $\eta_{\text {пр. }}$ (дл/г) $(1,2)$ и выход А (\%) (3) полимера 1 (табл. 1).

1 - раствор в ДМАА; 2 - раствор в $\mathrm{N}$ -

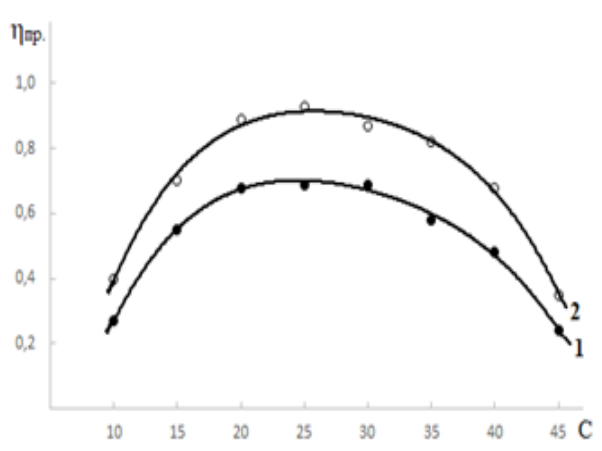

Рис. 2. Влияние концентрации С (\%) мономеров на приведенную вязкость $\eta_{\text {пр }}$ (дл/г) полимера 1 (табл. 1)

\section{МП}

Полимеры с максимальными значениями приведенной вязкости (молекулярная масса) образуются в интервале $120-140^{\circ} \mathrm{C}$ (рис. 1). При температурах ниже $120^{\circ} \mathrm{C}$ образуется низкомолекулярный полимер, что обусловлено низкой реакционной способностью мономеров с данных условиях. Повышение температуры реакционной смеси выше $140^{\circ} \mathrm{C}$, также не приводит к повышению молекулярной массы полимеров, что возможно, связано с увеличением скорости конкурирующих побочных процессов. На приведенную вязкость полимеров оказывает влияние концентрации мономеров в растворе. Зависимость приведенной вязкости о концентрации мономеров носит экстремальный характер (рис. 2).

С повышением концентрации до 20-25\% скорость взаимодействия мономеров оптимальна. Падение значений $\eta_{п р}$ с увеличением выше $25 \%$ обусловлено, очевидно, трудностями диффузии участвующих в реакции молекул в высоковязких растворах.

Таблица 1

Выход, приведенная вязкость и элементный состав ПИЭ

\begin{tabular}{|c|c|c|c|c|c|c|c|c|c|}
\hline \multirow[t]{2}{*}{$\mathrm{N}$} & \multirow[t]{2}{*}{$\mathrm{R}$} & \multirow[t]{2}{*}{$\mathrm{R}^{\prime}$} & \multirow[t]{2}{*}{$\mathrm{R}^{\prime \prime}$} & \multirow{2}{*}{$\begin{array}{c}\text { Вы- } \\
\text { ход, } \\
\%\end{array}$} & \multirow[t]{2}{*}{$\begin{array}{l}\eta_{\text {пр. }} \\
\text { дл/Г }\end{array}$} & \multicolumn{3}{|c|}{$\begin{array}{c}\text { Элементный состав, } \\
\% \\
\text { Вычислено/Найдено }\end{array}$} & \multirow[t]{2}{*}{$\begin{array}{l}\text { Брутто- } \\
\text { формула }\end{array}$} \\
\hline & & & & & & $\mathrm{C}$ & $\mathrm{H}$ & $\mathrm{N}$ & \\
\hline 1 & & $\hat{0}$ & - & 90 & 0,72 & $\begin{array}{c}92,48 / 8 \\
2,04\end{array}$ & $\begin{array}{c}5,73 / \\
5,91\end{array}$ & $\begin{array}{l}5,49 / \\
5,44\end{array}$ & $\mathrm{C}_{35} \mathrm{H}_{29} \mathrm{~N}_{2} \mathrm{O}_{2}$ \\
\hline 2 & & $-"-$ & - & 91 & 0,70 & $\begin{array}{c}79,65 / 7 \\
9,16\end{array}$ & $\begin{array}{l}4,59 / \\
4,63\end{array}$ & $\begin{array}{c}5,80 / \\
5,76\end{array}$ & $\mathrm{C}_{32} \mathrm{H}_{22} \mathrm{~N}_{2} \mathrm{O}_{3}$ \\
\hline 3 & & $-\ldots$ & - & 90 & 0,72 & $\begin{array}{c}84,38 / 8 \\
3,15\end{array}$ & $\begin{array}{c}5,13 / \\
5,27\end{array}$ & $\begin{array}{c}5,94 / \\
5,89\end{array}$ & $\mathrm{C}_{33} \mathrm{H}_{24} \mathrm{~N}_{2} \mathrm{O}_{2}$ \\
\hline 4 & & $-n-$ & - & 83 & 0,64 & $\begin{array}{c}82,38 / 8 \\
2,31\end{array}$ & $\begin{array}{l}4,75 / \\
4,84\end{array}$ & $\begin{array}{c}6,00 / \\
5,89\end{array}$ & $\mathrm{C}_{32} \mathrm{H}_{20} \mathrm{~N}_{2} \mathrm{O}_{2}$ \\
\hline
\end{tabular}




\begin{tabular}{|c|c|c|c|c|c|c|c|c|c|}
\hline 5 & & $-"$ & $3)$ & 95 & 0,76 & $\begin{array}{c}84,25 / 8 \\
4,16\end{array}$ & $\begin{array}{l}5,72 / \\
5,83\end{array}$ & $\begin{array}{l}4,64 / \\
4,61\end{array}$ & $\mathrm{C}_{42} \mathrm{H}_{34} \mathrm{~N}_{2} \mathrm{O}_{2}$ \\
\hline 6 & & $-n-$ & $-n-$ & 94 & 0,76 & $\begin{array}{c}81,79 / 8 \\
1,06\end{array}$ & $\begin{array}{c}4,92 / \\
4,98\end{array}$ & $\begin{array}{l}4,89 / \\
4,85\end{array}$ & $\mathrm{C}_{39} \mathrm{H}_{28} \mathrm{~N}_{2} \mathrm{O}_{3}$ \\
\hline 7 & & $-"-$ & - & 98 & 0,77 & $\begin{array}{c}84,18 / 8 \\
3,85\end{array}$ & $\begin{array}{l}5,29 / \\
5,38\end{array}$ & $\begin{array}{l}4,90 / \\
4,87\end{array}$ & $\mathrm{C}_{40} \mathrm{H}_{30} \mathrm{~N}_{2} \mathrm{O}_{2}$ \\
\hline 8 & & $-n-$ & $-"$ & 92 & 0,63 & $\begin{array}{c}84,14 / 8 \\
2,29\end{array}$ & $\begin{array}{l}5,07 / \\
6,35\end{array}$ & $\begin{array}{c}5,03 / \\
5,08\end{array}$ & $\mathrm{C}_{39} \mathrm{H}_{28} \mathrm{~N}_{2} \mathrm{O}_{2}$ \\
\hline 9 & 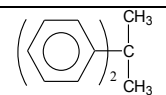 & $-n-$ & & 93 & 0,77 & $\begin{array}{c}81,97 / 8 \\
0,46\end{array}$ & $\begin{array}{c}5,36 / \\
6,06\end{array}$ & $\begin{array}{l}4,66 / \\
4,55\end{array}$ & $\mathrm{C}_{41} \mathrm{H}_{32} \mathrm{~N}_{2} \mathrm{O}_{3}$ \\
\hline
\end{tabular}

условия синтеза $-140{ }^{\circ} \mathrm{C}, \tau, 14$ ч

Найденные оптимальные условия синтеза позволили перейти к синтезу широкого круга ароматических ПИЭ (табл. 1). Выходы ПИЭ составляют 83-98\% от теоретического. Полимеры растворимы в ДМФА, ДМАА, N-МП, ДМСО, в растворителях фенольного типа и тетрахлорэтане. Строение полимеров установлено данными элементного состава (табл. 1) и ИК спектроскопии. В ИК области спектра наиболее характеристическими для ПИЭ является поглощение в области 1665-1645 (C= $\left.\mathrm{N}_{\text {ацикл }}\right), 1600\left(\mathrm{C}-\mathrm{C}_{\mathrm{ap}}\right), 1420(\mathrm{C}-\mathrm{N}), 1390,1280-1260$ см$^{-1}$ (C-O), свидетельствующие об образовании иминоэфирного фрагмента макромолекулы.

Химическая стойкость ПИЭ изучена по показателям приведенной вязкости полимеров до и после обработки их растворами минеральных, органических кислот и щелочей, при температуре $90-100^{\circ} \mathrm{C}$ в течение 48 ч (табл. 2).

Из приведенных данных следует, что ПИЭ более устойчивы к действию концентрированных минеральных и органических кислот, в концентрированных растворах $\mathrm{NaOH}$ наблюдается существенное снижение приведенной вязкости ПИЭ, особенно для поли-(С-фенил)иминоэфира, связь C=N в N-ПИЭ боковая, а в С-ПИЭ фрагмент основной цепи макромолекулы. Данное обстоятельство позволяет сделать вывод о первоочередном гидролизе $\mathrm{C}=\mathrm{N}$ связей.

Таблица 2

Химическая стойкость ПИЭ

\begin{tabular}{|c|c|c|c|c|c|c|}
\hline \multirow{2}{*}{ №* } & \multirow{2}{*}{ 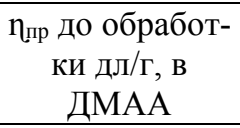 } & \multicolumn{5}{|c|}{ ппр после обработки дл/г } \\
\hline & & $\mathrm{H}_{2} \mathrm{SO}_{4}$ (к) & $\mathrm{HCl}$ & $\mathrm{HCOOH}$ & $\mathrm{CH}_{3} \mathrm{COOH}$ & $\mathrm{NaOH}(к)$ \\
\hline 1 & 0,76 & 0,70 & 0,66 & 0,70 & 0,71 & 0,16 \\
\hline 2 & 0,70 & 0,65 & 0,63 & 0,65 & 0,08 & 0,15 \\
\hline 4 & 0,64 & 0,52 & 0,50 & 0,60 & 0,61 & 0,18 \\
\hline 5 & 0,76 & 0,51 & 0,72 & 0,65 & 0,66 & 0,01 \\
\hline
\end{tabular}

* номера полимеров соответствуют полимерам в табл. 1 .

Результаты ТМА и ТГА приведены в табл. 3. Температура пластической деформации ПИЭ в пределах $225-390^{\circ} \mathrm{C}$. Согласно данным динамического термогравиметрического анализа наиболее стойкими к термоокислительной деструкции являются ПИЭ, которые не содержат алифатических групп $-\mathrm{CH}_{2}-$ и $-\left(\mathrm{CH}_{3}\right)_{2}-$. 
Могнонов Д. М., Аюрова О. Ж., Ильина О. В., Хахинов В. В. Синтез и исследование ароматических полииминоэфиров

Таблица 3

Термические и физико-механические свойства ПИЭ

\begin{tabular}{|c|c|c|c|c|c|}
\hline № & $\begin{array}{c}\text { Температура } \\
\text { размягчения*, } \\
{ }^{\circ} \mathrm{C}\end{array}$ & $\begin{array}{c}\text { Температура } \\
\text { начала разло- } \\
\text { жения**, }{ }^{\circ} \mathrm{C}\end{array}$ & $\begin{array}{c}\text { Прочность } \\
\text { при разрыве, } \\
\text { МПа }\end{array}$ & $\begin{array}{c}\text { Относительное } \\
\text { удлинение при } \\
\text { разрыве, \% }\end{array}$ & $\begin{array}{c}\text { Ударная } \\
\text { вязкость, } \\
\text { кДж/. }{ }^{2}\end{array}$ \\
\hline \multicolumn{6}{|c|}{ N-ПИЭ } \\
\hline 1 & 230 & 385 & 43 & $3-4$ & $7,5-8,0$ \\
\hline 2 & 315 & 460 & 40 & - & - \\
\hline 4 & 365 & 490 & 35 & $2-3$ & - \\
\hline \multicolumn{7}{|c|}{ С-ПИЭ } \\
\hline 5 & 225 & 365 & 44 & $3-4$ & $7,5-8,5$ \\
\hline 6 & 390 & 465 & 42 & $2-4$ & $6,5-7,0$ \\
\hline 8 & 325 & 405 & 43 & $2-3$ & $6,5-7,5$ \\
\hline
\end{tabular}

номера полимеров соответствуют табл. 1 ; * температура 5\%-ной деформации, при нагрузке 0,33 МПа; ** температура 5\%-ной потери массы, на воздухе.

Хорошая растворимость и достаточно большой интервал между показателями тепло- и термостойкости открывает возможность переработки синтезированных ПИЭ в полимерные материалы современными промышленными методами. Так, пресс-образцы (без наполнителя), полученные прямым прессованием при 245$400^{\circ} \mathrm{C}$ и удельном давлении 75 МПа характеризуются достаточно хорошими физико-механическими показателями.

\section{Выводы}

1. Реакцией неравновесной поликонденсации имидоилхлоридов моно- и дикарбоновых кислот с бисфенолами получены поли-(N-фенил)- и поли-(С-фенил)иминоэфиры, показано строение методами элементного анализа и ИКспекстроскопии.

2. В результате изучения термических свойств ПИЭ показано, что их отличает высокая термостойкость и большой интервал температуры начала разложения и размягчения.

3. Пресс-материалы на основе ПИЭ, полученные прямым прессованием характеризуются высокими деформационно-прочностными показателями, сравнимыми с материалами на основе ароматических полиамидов и полибензимидазолов.

Работа выполнена в рамках государственного задания Байкальского института природопользования СО РАН.

Литература

1. Коршак В. В. Термостойкие полимеры. М.: Наука, 1969. 411 с.

2. Бюллер К. У. Тепло- и термостойкие полимеры. М.: Химия, 1984. 1056 с.

3. Коршак В. В. Химическое строение и температурные характеристики полимеров. М.: Наука, 1970. 419 с.

4. Фрейзер А. Г. Высокотермостойкие полимеры. М.: Химия, 1971. 294 с.

5. Kurita K., Kusayama L., Iwakura Y. Polyadditions of bisketenimines. I. Syntesis of polyamidines from bisketenimines and diamines // J. Polym. Sci., Polym. Chem. Ed. 1977. № 9. P. 2163-2173. 
6. Ogata S., Kakimoto M., Imai Y. Direct synthesis of new aromatic polyamidines from aromatic diamides and benzoic acids by using poly(trimethylsilylphosphate) // Macromol. Chem., Rapid Commun. 1985. V. 6, № 12. Р. 835-839.

7. Токтонов А. В., Могнонов Д. М., Мазуревская Ж. П., Батоева С. О. Синтез полиамидинов на основе ароматических бисимидоилхлоридов в растворе // Высокомолекулярные соединения. Сер. А. 2006. Т. 48, № 1. С. 5-15.

8. Crenda V. Y., Jones R. E., Stetzinger M. Benzimidazoles from N-arylamidines. New Synthesis of thiabendazole // J. Org. Chem. 1965. V. 30, № 1. P. 259-261.

\section{SYNTHESIS AND RESEARCH OF AROMATIC POLYIMINOESTERS}

Mognonov D. M.

Doctor of Chemical Sciences, Professor

Baikal Institute of Nature Management SB RAS

670047, Ulan-Ude, Sakhyanovoi Str., 6

Buryat State University

670000, Ulan-Ude, Smolina Str., 24a

E-mail:dmog@mail.ru

Ayurova O. Zh.

Candidate of Technical Sciences

Baikal Institute of Nature Management SB RAS

670047, Ulan-Ude, Sakhyanovoi Str., 6

Buryat State University

670000, Ulan-Ude, Smolina Str., 24a

E-mail: chem88@mail.ru

Ilina O. V.

Candidate of Technical Sciences

Baikal Institute of Nature Management SB RAS

670047, Ulan-Ude, Sakhyanovoi Str., 6

Khakhinov $V . V$.

Doctor of Chemical Sciences, Professor

Buryat State University

670000, Ulan-Ude, Smolina Str., 24a

E-mail:khakhinov@mail.ru

The synthesis of aromatic polyiminoesters by polycondensation of bis-imidoyl chlorides with diamines was performed. Optimal conditions for polycondensation processes with various nucleophiles were determined. The reaction of non-equilibrium polycondensation of imidoyl chlorides of mono-and dicarboxylic acids with bisphenols produced new polymers, the structure of which was established by elemental analysis and IR spectroscopy. It is shown that polymers have high temperature resistance. Press materials based on them, which are characterized by high deformation and strength indicators comparable to materials based on aromatic polyamides and polybenzimidazoles, were studied.

Keywords: nonequilibrium polycondensation; high temperature resistant polymers; diamines; polyaminoesters; polybenzimidazole; press materials; deformation-strength characteristics. 